MISTRAL MISTRAL

Journal of Latin American Women's

Intellectual \& Cultural History

\title{
"Morir antes que esclavas vivir": La voz que cuenta en 98 segundos sin sombra de Giovanna Rivero
}

Laura A. Arnés, Universidad de Buenos Aires / UNTREF / CONICET, Argentina

Silvana Abal, Universidad de Buenos Aires, Argentina

To cite this article: Laura A. Arnés y Silvana Abal. 2021. “'Morir antes que esclavas vivir': La voz que cuenta en 98 segundos sin sombra de Giovanna Rivero." Mistral: Journal of Latin American Women's Intellectual \& Cultural History 1 (2): 10-19, https://doi.org/10.21827/mistral.2.38024

\begin{abstract}
This article analyses 98 segundos sin sombra (2014) by Giovanna Rivero, one of the most representative writers of Bolivian "new narrative." 98 segundos problematizes the gendered matrices of culture, foregrounding young and feminized fictional subjectivities that exercise disobedience as a mode of self-determination. Through the re-appropriation of family history and imposed affects, the protagonists build alternative ways of existence by practising detours and deviations, expressing what Julia Kristeva terms "revolt." These "revolts" establish a conflictive link with the past and, at the same time, emphasize uncertainty about the future. They enable the possibility of distancing oneself from one's own memory, giving rise to new figures of temporality and calling into question the idea of "civilization."
\end{abstract}

\section{Keywords}

Bolivian Literature; Giovanna Rivero; Gender Studies; Young lives; Alternative forms of living

\section{Resumen}

Este artículo analiza 98 segundos sin sombra (2014) de Giovanna Rivero, una de las escritoras más representativas de la "nueva narrativa" boliviana. 98 segundos problematiza las matrices generizadas de la cultura, al construir subjetividades ficcionales jóvenes y feminizadas que ejercen la desobediencia como modo de autodeterminación. En la reapropiación del pasado familiar y de los afectos impuestos, las protagonistas operan sobre ellos desvíos que les permite construir modos de existencia alternativos, "re-vueltas" (Kristeva, 1998) que instalan un vínculo conflictivo con el pasado al tiempo que alojan la incertidumbre sobre el futuro; que habilitan la posibilidad de distanciarse de la propia memoria y dan lugar a nuevas figuras de la temporalidad, llegando a poner en crisis la misma idea de "civilización."

\section{Palabras claves}

Literatura boliviana; Giovanna Rivero; Estudios de género; vidas jóvenes; Formas de vida alternativas 


\title{
"Morir antes que esclavas vivir": La voz que cuenta en 98 segundos sin sombra de Giovanna Rivero
}

\author{
Laura A. Arnés, Universidad de Buenos Aires / UNTREF / CONICET, Argentina \\ Silvana Abal, Universidad de Buenos Aires, Argentina
}

\author{
No quiero conocer mi futuro. No quiero \\ que saque a la luz ningún quiste del pasado. \\ Selva Almada, Chicas muertas \\ Es fácil ser hombre. Es facilísimo. \\ Abrís la boca y reís. \\ Giovanna Rivero, 98 segundos sin sombra
}

En los últimos años, Giovanna Rivero Santa Cruz aparece en el heterogéneo campo de la literatura boliviana como figura destacada de lo que dio en llamarse "nueva narrativa". ${ }^{1}$ La crítica la reconoce como una renovadora tanto del realismo como del fantástico y resulta evidente que en sus obras confluyen diversas tradiciones: el gótico, la ciencia ficción, el western, la novela erótica o la Bildungsroman. Desde esta diversidad formal, su escritura ha puesto el foco en la cuestión del cuerpo: corporalidades enfermas, hambreadas, heridas, despojadas, deseantes, olvidadas o muertas, marcadas por la pertenencia latinoamericana, pueblan sus cuentos y novelas; y la figuración de vidas jóvenes resulta central en su escritura no sólo para plantear una reflexión en torno a los modos de existencia contemporáneos sino para revisar el pasado histórico, político y cultural boliviano.

Escrita en primera persona, 98 segundos sin sombra (2014) pone en primer plano una voz femenina y joven, dando lugar a un corrimiento inicial: frente a la tradición histórica y literaria que instala la escritura femenina y adolescente en el género "diario íntimo", lo que Genoveva Bravo Genovés escribe, explícitamente, no lo es ("este cuaderno cuadriculado tapa dura sin pretensiones de "diario", 19). Esta gestualidad, que se inscribe tácitamente en los debates en torno al sexismo de los géneros literarios, resulta acto fundante a partir del cual la novela problematizará las construcciones del sentido común, las normas comunes, las matrices generizadas de la cultura y las consideraciones en torno al valor de la vida.

Extremadamente consciente del funcionamiento de lo social, Genoveva, a lo largo del relato, se va a ir construyendo a sí misma como intérprete privilegiada de las batallas en torno a lo que es públicamente decible -y goza de legitimidad y escucha- $y$ deseable en un determinado escenario. Pero, además, en su escritura queda cristalizado un orden biopolítico que se inscribe bajo la seña de su fracaso: como veremos, el protagonismo lo tiene aquello que los cuerpos pueden; eso que la cultura no pudo o puede disciplinar. Así, podría pensarse que, en serie con cierta zona de la literatura latinoamericana contemporánea, esta novela tiene como rasgo central: "Dar lugar a lo

\footnotetext{
${ }^{1}$ Para más información, ver: Sergio Di Nucci, Nicolás G. Recoaro y Alfredo Grieco y Bavio (eds.), De la Tricolor a la Wiphala. Narrativa contemporánea de Bolivia. Buenos Aires, Santiago Arcos editor, 2014.
} 
que se niega, presenciar las no presencias, excavar en los escombros, traer a la imagen los cuerpos negados" (Quintana 2020, 139) y hace evidente -o denuncia- que la cultura contemporánea no puede construirse sino sobre restos, al tiempo que propone proyectos vitales alternativos. ${ }^{2}$

Como nota Martín de Mauro (2015), en los debates teóricos actuales que giran en torno a la condición precaria se hace hincapié en un tipo de vida corporal expuesta y en relación de dependencia con otros, definida en gran medida por su vulnerabilidad física. Pero ciertos recorridos de la cultura latinoamericana contemporánea traen a la superficie no sólo una lógica política, una racionalidad de gobierno o una vida corporal configurada por la exposición mutua y la vulnerabilidad, sino singularidades que abren umbrales de politización y que modulan lo estético, lo sensible y los afectos, la temporalidad y la vida no-humana junto con la dimensión epocal: "De lo que se trata es de un ser viviente que está siempre más allá de sí mismo, rebasando la esfera del individuo, sus formas y figuras preestablecidas (...), conservando su propia capacidad normativa de establecer nuevas normas" $(2015,23)$. Si leemos el cuaderno de Genoveva con esto en mente ya no resulta (solamente) una construcción de su ámbito íntimo, sino una puesta en escena de su propio bios precario, del desfasaje entre la experiencia vivida y la memoria, y esto no sólo porque ella se presenta como un ser con un lenguaje auto-expropiado -"me la paso colocando comillas, es como si yo no tuviera un lenguaje propio" (49)-, sino también porque el ejercicio de su memoria entra en contradicción con el no reconocimiento de su propia vida como una vida legítima: "Ella [madre] nunca dice 'tu vida', dice 'tu futuro'. Y 'tu futuro' es una forma de mandarme a dormir, de que no joda, de que no pregunte" (50). Las vidas jóvenes que figura la novela resultan así precarias, justamente, porque se construyen en una paradoja: dedicadas al desarrollo o progreso se encontrarían continuamente atascadas en un tiempo de supervivencia, de movimiento y dilación, en un lugar "en el que no es posible descansar" (Berlant 2011, 114).

El escenario del relato es Therox, un pueblo ficcional y polvoriento, un suburbio cruceño cada vez más devastado por las plantaciones de coca y la violencia de los "pichicateros". Aunque "todo queda muy lejos, tan lejos que he llegado a creer que nada en el Universo existe" (39) el imperio norteamericano sí está cerca: los agentes de la DEA son casi omnipresentes y las referencias musicales y cinematográficas de las adolescentes toman siempre el rumbo de Hollywood y Studio 54. Al ser un puente entre grandes ciudades, en Therox el dinero es "invisible", la suerte de sus habitantes está signada por el "decreto maldito", ${ }^{3}$ hay más autos que asfalto y su monumento es "un héroe que empuña una espada inútil contra el tiempo nuevo" (40). Allí vive Genoveva Bravo Genovés - el mismo apellido parece laurear hazañas pasadas- y su familia: un padre marxista y deprimido que fracasó en su propio suicidio, una madre "linda, callada, fantasmal" (57) que se reúne con otras mujeres bajo la mirada del Maestro

\footnotetext{
2 Bajo nuestra perspectiva de análisis, este texto comparte problemas y tópicos con otros relatos latinoamericanos tan diversos como los argentinos Las primas y Nosotros, los Caserta (Venturini 2007 y 1992), Las Malas (Sosa Villada 2019), El niño pez (Puenzo 2004) o El país del diablo (Suez 2015) y los bolivianos Hablar con los perros (Urrelo Zárate 2011), El lugar del cuerpo (Hasbún 2009) y Nuestro mundo muerto (Colanzi 2016).

${ }^{3}$ El 29 de agosto de 1985, el presidente Víctor Paz Estenssoro firmó el Decreto Supremo 21060, que inaugura la política neoliberal en Bolivia y habilita la privatización de las empresas estatales, la venta de recursos naturales, la pérdida de derechos laborales, la desregulación del mercado y la dolarización de la economía.
} 
Hernán a descubrir "Las enseñanzas de Ganimedes", ${ }_{4}^{4}$ un hermanito baboso con un "desfase oligofrénico" (49) y Clara Luz, la abuela un poco bruja a quien, sobre el final, la protagonista eutanasiará. Vive en Therox también Inés, su mejor amiga anoréxica, quien sueña con desaparecer completamente, y Vacaflor: "la madonna gorda de aliento a chocolatitos" (63) que, como consecuencia de una relación casual de dudoso consenso con un profesor, se provocará un aborto en el baño de colegio, con la asistencia de Genoveva.

La melancolía paterna por un pasado glorioso y nacionalista, las políticas neoliberales recién estrenadas, el avance del narcotráfico y la consiguiente penetración norteamericana, el cristianismo militante de la escuela, las creencias sincréticas de la madre y abuela de la protagonista, el ímpetu por la vida y la supervivencia del cuerpo de la práctica médica son todos elementos que se constituyen en el texto como dispositivos aleccionadores del cuerpo y de la afectividad de Genoveva (que parecerían estar siempre fuera de lugar). Sin embargo, todos se resquebrajan bajo la mirada y las acciones de las jóvenes. Pero, además, resulta claro que la novela capta un momento o, mejor dicho, da lugar a un estado (afectivo y político) en el que la familia se presenta para siempre "mutilada" (Roudinesco 2002): por más que se insista, ya no tiene cabida ese orden familiar económico burgués que se apoya en la autoridad del marido, la subordinación de las mujeres y la dependencia de les niñes.

La escritura de Genoveva registra meticulosamente las interpelaciones que pretenden definirla: escucha a las monjas llamarla a ella y a sus compañeras de escuela "capullo" (15) o "fruto verde" (23); ve a su padre mirarla con ira, pensando que "no sabe ni limpiarse el culo" (60), desconfía de su madre que no la ve como una persona que tiene una vida, sino como alguien que tiene un "futuro" (9). El transcurrir del relato, en su insistencia, vuelve evidente que los modos del decir o las formas de nombrar que definen las relaciones siempre delatan una matriz social y política, es decir, ideológica, afectiva e imaginaria (Butler 2011). Así, nuevamente, la literatura se vuelve ocasión para pensar también los modos de la cultura porque, sin lugar a duda, la literatura es uno de los dispositivos políticos donde se modulan distribuciones alternativas de lo que afecta a nuestros mundos sensibles, un espacio privilegiado en el cual se ensayan formas posibles (probables o improbables) de la vida en común y en donde, como consecuencia, se estrenan constantemente nuevas relaciones entre los cuerpos; o entre los cuerpos y sus voces.

Si en la literatura latinoamericana de este siglo proliferan las imágenes de cuerpos vulnerados y descartados, en esta novela estos cuerpos buscan agenciamientos disruptivos y márgenes de autonomía: buscan resistir. Si la orden de la cultura es vivir como se manda, las jóvenes protagonistas procuran decidir el cómo pero también el hasta cuándo. Frente a los órdenes establecidos, a las disposiciones proyectivas y a las construcciones sobre los cuerpos, el relato de Rivero se rebela y resulta, inmediatamente, peligroso: desprecia los binarismos de la cultura occidental, violenta los modos de las temporalidades teleológicas y (re)productivas, transita otros recodos de la memoria, cuestiona el ideal de felicidad, propone nuevos arreglos familiares e, incluso, reivindica la muerte como acto de libertad o liberación. De este modo, la escritura de Genoveva también pone en escena la pregunta -y atina una respuesta posible- a esa pregunta que esboza Gabriel Giorgi al leer otra zona de la cultura

\footnotetext{
${ }^{4}$ Ganímedes es un personaje de la mitología griega también conocido como el Aguador, símbolo del signo de acuarius que anuncia la Nueva Era del Saber. En la novela, Ganímedes es concebida como una suerte de otra dimensión habitable en el espacio exterior, a la que es posible llegar de diversas formas "hay gente que ha viajado a Ganímedes a través del tronco de un árbol (173).
} 
latinoamericana: "¿cómo respondo con mi cuerpo a las marcas que me imponen un lugar en las cartografías políticas?” $(2014,20)$

Con esta misma preocupación, Athanasiou y Butler se preguntan al momento de pensar la "desposesión”: ¿Qué pasa cuando "el lugar propio es el no-ser”? (2017, 35) Si bien las autoras no están considerando los problemas que atraviesan las identidades englobadas en los conceptos de "juventud", "adolescencia" o "niñez" (ni tampoco las latinoamericanas en su especificidad), nos interesa recuperar esta pregunta para problematizar esa identidad - central en la novela que estamos leyendo- que, paradójicamente, se sostiene sobre su propia negación; esa subjetividad, la "adolescente", que articula violencias y daños diferenciales y que, como bien nota Genoveva, implica una desubjetivación esencial y una falta de reconocimiento: "mi vida es la imposibilidad" (59). Y es que la juventud precaria se sostiene sobre un problema temporal: el fracaso en la gestión de su propio tiempo.

Si las vidas "jóvenes" se definen, bajo la mirada adulta, en tanto potencia o en su potencial, si son construidas como "subjetividades espectrales"5 (Athanasiou 2015, 379), la vida joven no existe en presente, no se hace presente. Esta dislocación temporal inscribiría un borramiento, una ausencia, que en la novela de Rivero es puesta en escena una y otra vez. Incluso podría pensarse que funciona como motor narrativo. De hecho, el título hace referencia a un acto de agenciamiento frente a la desposesión fundante: "98 segundos sin sombra" es el tiempo que se puede poseer la propia sombra, "cuando nada de la realidad me divide y estoy en control de todo lo mío, sin refractación, sin proyección (...) Yo total" (94). Ese momento sin sombra son también, dice Genoveva, "los segundos de Inés" (94), quien mientras ve su cuerpo desaparecer del suelo, puede olvidarse de su familia y de su deseo de convertirse en "estado gaseoso" (95).

Si en la figura de la "niñez" Occidente condensa sentidos -siempre políticos y afectivos- de futuridad colectiva, de ciudadanía ideal, de esperanza, es decir, de orden social -"lo que hay más allá no está por crearse, sino que ya está hecho, esperando" (61), reconoce lúcidamente la narradora de 98 segundos...-, la infancia y/o la adolescencia irrumpen aquí para negarlos, para clausurar las fantasías dominantes, para proponer otros modos de habitar (en) el presente. En esta línea, Lee Edelman (2014), al pensar el campo cultural norteamericano, sostuvo que "la queeridad nombra el lado de aquellos que "no luchan por los niños", el lado exterior a ese consenso según el cual "toda politica confirma el valor absoluto del futurismo reproductivo (...); la queeridad (...) figura (...) el lugar de la pulsión de muerte del orden social (...)" (20). Pero en el escenario más al sur que 98 segundos sin sombra construye, son las propias niñas quienes (sin la palabra queer que las contenga, pero con el mismo impulso) resisten la viabilidad de lo social: son ellas mismas quienes rechazan ser consideradas emblema de futuridad e imponen resistencia a ser convertidas en capital o en inversión.

\section{Somos disfuncionales y qué, lo que está mal es el sistema}

El padre de Genoveva es trotskista, alcohólico y suicida frustrado. Fracasado hasta en su propia voluntad de morir, esclavo de los relatos del pasado y, paradójicamente, también del dinero, forma parte de una generación que no sólo nunca tendrá una epopeya, sino que está signada por la decepción, e insiste en compartir con ella esa condena. El único regalo que alguna vez le dio a su hija fue El diario de Ana Frank y,

\footnotetext{
${ }^{5}$ Subjetividades que solo existen en el borramiento/desplazamiento/disidencia de las matrices normativas e ideológicas humanistas, liberales y heterosexistas que definen las identidades de los sujetos.
} 
luego de leerlo, la conclusión de la joven fue adorniana: después de esa experiencia, todo es una nimiedad; después de esa lectura nada donde ella escriba podrá ser llamado diario, tal vez cuaderno o agenda, pero nunca diario. Luego de esa reflexión, reconoce que el obsequio fue "malintencionado" (17) y que su padre está obsesionado por las experiencias de sus mayores y por sus testimonios, los testimonios sobre la Segunda Guerra, sobre Vietnam o sobre la Guerra del Chaco, es decir, sobre experiencias traumáticas e históricamente relevantes que legitiman los relatos del yo al colectivizarlos.

Con una perspectiva feminista tácita, la joven promete "limpiarse el culo" (60) con las palabras que le enseñan en el colegio, reconoce que es injusto que cuando hablan de "el Hombre" en Filosofía también se dirijan a ella y capta la ironía de tener que pedir permiso para cantar como quiere un himno nacional que declama "libertad". Sin embargo, no logra deshacerse de la palabra paterna tan fácilmente: las enseñanzas de su progenitor serán incorporadas y apropiadas a través de desvíos: "Voy a usar las palabras de Padre: 'una garra'. Él lo dice en mala onda, para referirse a los militares, pero la idea me sirve" (48). De igual forma, si el padre entiende la frase de Scott Fitzgerald -"Y así vamos adelante, botes contra la corriente, incesantemente arrastrados hacia el pasado" (32) - en términos marxistas, como alusión a las crisis cíclicas del capitalismo, ella la parafrasea desde el aspecto familiar y afectivo: "Avanzo entre escombros, basura que tiró otra gente, desechos de Padre, cáscaras de Madre" (54).

Hay en esa reapropiación lingüística y cultural una reevaluación de su pasado y del pasado que comparte con sus padres. Si, históricamente, como nota Élisabeth Roudinesco y como la novela bien pone en escena, "la vocación discursiva delega en el padre un ideal de dominación que le permite alejar a su progenitura de la bestia, la animalidad, el adulterio y el mundo de los instintos, encarnados por la madre" (2010, 24), en el caso de Genoveva la reformulación del lenguaje y del bagaje paterno y la apropiación de las prácticas espirituales de su madre no contribuyen a la creación de un espacio familiar y afectivo sino a la construcción consciente de una nueva forma de habitar, a la posibilidad de hacerse de una vida vivible; así resignifica el espacio simbólico en que le toca existir y crea nuevas posibilidades y alianzas. En este sentido, su devenir constituye lo que Donna Haraway (2019) denomina un "relato en marcha", que no se decanta por la condena ni la celebración, sino que transita críticamente entre los lazos heredados y los nuevos afectos.

En la cita que reformula a Fitzgerald, el decir "desecho" y "cáscara" para referirse respectivamente a su padre y a su madre no es casual: Genoveva entiende a su progenitor como un despojo humano que mejoraría sus vidas "si tuviera la decencia de morirse" (7). Genoveva contempla en silencio a la "Llorona bonita" (56) que terminó siendo su madre y piensa: "Pobre Nacho", porque su madre aúlla junto a otras mujeres en un templo, camina hasta ampollarse los pies, llora todas las noches y duerme por las mañanas, e inmediatamente ratifica, citando a la banda de pos-punk inglesa, Joy Division: "Somos disfuncionales y qué, lo que está mal es el sistema" (51). Ni ellos ni ella están mal: el problema es la normativa de cumplir ciertos roles imposibles o, incluso, contra la propia voluntad; el problema es la necesidad de mantener las apariencias, de sostener los vínculos de sangre como fundamentales. Pero, además, si consideramos que la familia se organiza de acuerdo con imagos, con representaciones inconscientes (y no tanto) que garantizan su incorporación de los sujetos en la matriz del género y su consiguiente humanización, ¿qué sucede cuando estos pactos afectivos, imaginarios, económicos y políticos se rompen o, por lo menos, delatan su ficción? 
Genoveva piensa que si su madre no los tuviera a ellos o a un esposo deprimido sería feliz. Ella se reconoce como carga, pero va más allá y reconoce que sus padres son también otra carga, aún más pesada: "Ojalá me enterara de que soy adoptada y de que esos lazos, que las monjas dicen que son sagrados, desaparecieran de una vez" (82). Asimismo, comprende que lo sagrado solo cede ante la traición, que solo puede o debe ser sagrado lo que se elige. Y por eso decide huir, pero a un lugar conocido: traicionará a su padre -le robará los ahorros- y escapará con el Maestro Hernán, iniciador de su madre en las Enseñanzas de Ganímedes. A primera vista, la huida casta parece un cliché de melodrama: una adolescente pueblerina se fuga con un hombre mayor para salvarse. Sin embargo, lo que la protagonista hace es trastocar las funciones y ejercer de forma voluntaria, completa y consciente lo que su madre ha hecho a modo de máscara. Se llevará además a su hermano pequeño, sobre quien ejercerá, descarriadamente, las tareas de cuidado "maternas" proponiendo una forma, algo teatral, de hacer lazos, familias o parentescos que se distancian de los mandatos biológicos, del acto sexual y la sangre: "Me levanto la polera y le ofrezco mi pecho diminuto. Nacho se prende, gorjea, se va acomodando como un embrión. Así, viajando, los tres somos una nueva civilización" (174. El resaltado es nuestro)

La nueva Genoveva, renacida y auto-bautizada "Isis" -"Yo ahora soy una Isis, digo, llena de fe" (172)- dará lugar a procesos que implican simultáneamente una recuperación y una renovación. La marcha y el nuevo comienzo de la protagonista aparecen como esa "re-vuelta" (Kristeva 1998) que instala un vínculo conflictivo y cuestionador con el pasado, al tiempo que aloja la incertidumbre sobre el futuro; que habilita la posibilidad de distanciarse de la propia memoria y da lugar a nuevas figuras de la temporalidad. Ser una nueva civilización es también instalar otra forma de hacer comunidad; inaugurar una nueva ética que sabe de rabia y vulnerabilidad y que, por eso, se entrega, sin miedos, a los riesgos y al poder de lo imposible y lo desconocido.

\section{Fear me you lord and lady preachers}

Las monjas salesianas que guían la educación de Genoveva y sus compañeras recuerdan, ante cualquier disquisición moral, a Laurita Vicuña, una niña chilena que murió a los doce años azotada por una grave enfermedad y cuyo compromiso con la fe católica le había valido la beatificación en 1988. La escuela tiene en su entrada un maniquí (no una figura) de la santa y, según Genoveva, es para enseñarles sobre códigos de etiqueta, porque no vaya a ser cosa que no sean humildes, puras y correctas al vestirse. En la misma dirección, también les enseñan cómo usar el lenguaje y les piden que armen oraciones con palabras como "infatuar", "redención" o "pecaminoso" y les permiten, llamativamente, pronunciar en femenino la estrofa del himno nacional que dicta: "Morir antes que esclavos vivir".

La enunciación degenerada de la frase se visibiliza, en la novela, cargada de nuevos sentidos al desplazarse, por contigüidad, de su tradición patriótica-liberal y cristiana $^{6}$, para inscribirse en la orden biopolítica del "hacer vivir": así como Inés busca activamente el abandono de su propio cuerpo, dejar de ser prisionera de su "naturaleza óseo-lipidinosa" (96), otros personajes ejercerán el derecho de "hacer morir": "Livy

\footnotetext{
${ }^{6} \mathrm{Si}$ bien nosotras no nos centramos en la función de los imaginarios cristianos en la novela, no podemos dejar de notar que la imagen de la "esclava del Señor" es central en el cristianismo. En este sentido, la enunciación "degenerada" del himno, habilitada por las monjas salesianas, arrastraría otra serie de problemas interesantes y complejos para el análisis.
} 
Soler", por ejemplo, "le había pegado un tiro entre ceja y ceja a su violador y eso nadie podría cambiarlo" (153). Genoveva, por su parte, también ejercerá el derecho de "hacer morir" pero no a modo de castigo sino en tanto gesto de piedad que reconoce con afecto el momento en que el cuerpo de su abuela ya no es habitable y ha dejado de ser apto para una vida vivible: "Cerré la llave del tanque. Besé las manos venosas de Clara Luz, le acaricié un momento los pies, que estaban fríos, pero luego me aparté. La propia Clara Luz me había contado que el alma sale por los pies" (163).

Las pulsiones de vida y muerte como modos de definir la existencia cotidiana se entrelazan en otro hecho crucial: el aborto de Vacaflor. La adolescente ha tenido "una sola vez" (111) relaciones sexuales con Quishpe, su profesor de Sociales. Fruto de ese encuentro ha quedado embarazada de un "hijo" que tendría "trece años y un mes y medio para cuando llegue el fin del mundo" (110), es decir, en el año dos mil. El tiempo marca los límites de la vergüenza y de la urgencia: el tiempo que pasa hace que "eso" que tiene en su vientre crezca y la arroje hacia una decisión: "Tomé algo para esto. Se supone que voy a botar el bicho en cualquier momento" (115. El resaltado es nuestro), le confiesa a Genoveva. La animalización del feto sorprende a Genoveva, pero luego ella misma reconocerá lo adecuado del nombre: "con asco absoluto tomo al sapo humano y lo largo al inodoro. Tiro la cadena y el sapo se resiste, reflota como la peor de las mierdas, la más rebelde" (117). La metaforización del feto abortado ahora en términos de "mierda que reflota" cifra al acto mismo como un atentado contra los preceptos de religiosidad y ejemplaridad femenina que profesan en la escuela y en el pueblo, como una infracción al doble mandato que daría forma al cuerpo y a las subjetividades de las mujeres: el de virginidad y el de maternidad. Pero, además, nuevamente, la novela se inscribe como contradiscurso al despreciar esa figura, la del feto, que en la narrativa heterosexista tiende a instituirse, como sostiene Berlant (2011) en tanto forma modal y futura de ciudadanía.

\section{Should I stay or should I go}

Dentro de las genealogías afectivas que la voz que cuenta delinea se produce un corrimiento de los ideales humanistas, de los modelos normativos que establece la matriz generizada del heterocapitalismo y, por ende, se suceden acercamientos $-\mathrm{o}$ asociaciones- con lo animal. En este sentido, el relato de Rivero confirma o enriquece las ideas desarrolladas por Giorgi (2014): la aparición de lo animal permitiría, en la novela, cuestionar las lógicas de distinción -ese régimen de jerarquización biopolíticasurgida de los ideales modernos $\mathrm{y}$, por tanto, también disputaría los valores civilizatorios del humanismo.

Bajo esta perspectiva, la condición del embrión (antes referenciada) también arma serie con la figura de Nacho, ese niño fatídico, sin potencial futuro, que de "batracio nonato" pasa a "lechuza bebé" (27), "babosa" (28) o "ranita feliz" (86): "Nacho, en cuestión de tres segundos y medio, se revela como un animalito" (27). La animalidad del bebé se presenta, así, como forma desviada de visibilización, pero también de reivindicación de ese cuerpo sobre el que pesa el estigma de la anormalidad; y su figuración incierta instala alternativas a la enfermedad, pero también a la

\footnotetext{
${ }^{7}$ En el cuento "La mansedumbre", publicado en Tierra fresca de su tumba (2020), Giovanna Rivero aborda nuevamente los tópicos de la violación y la justicia por mano propia en el marco de la religiosidad ortodoxa, pero lo incluye dentro de la cosmovisión aymara, donde en cierta forma la venganza no se concibe como un acto individual, sino como evento de retribución y redención colectiva.
} 
genealogía y a la biología de quienes con el se asocian: a modo de ejemplo están los pechos de Genoveva, la hermana devenida madre, que crecen "gracias a las chupadas de Nacho" (42). Así, el relato parecería acordar con Halberstam en que la: "Queer culture (...) resists a developmental model of substitution and instead invests in what Stockton calls "sideways"relations, relations that grow along parallel lines rather than upward and onward. This queer form of antidevelopment requires healthy doses of forgetting and disavowel." (2011, 73). Los marcos temporales estables de la heteronormatividad y la (re)producción capitalista se ven, así, alterados, afectando en el mismo gesto, la definición burguesa de "civilización".

Por otro lado, la gordura de Lorena Vacaflor - la madonna con la "ligereza de un mono" (72), la que lleva en su apellido la marca escarlata, aserto de lo inhumano-, y la delgadez de Inés son dos extremos que también marcan los límites del cuerpo humano. Su carne y su voluntad indisciplinada no solo reconfiguran los contornos de los jóvenes cuerpos, politizándolos al desafiar su estado "natural", sino que ponen en crisis los paradigmas reproductivos y de fertilidad femenina ("Inés tocó la manchita con el índice esquelético. A mí, hace un siglo que no me viene, dijo", 154). Además, hacen reaparecer la pregunta sobre los estándares de belleza y los registros de salud o bienestar, poniendo en escena de modo "torcido" dos fantasmas del capitalismo contemporáneo que conmueven a Latinoamérica y que también deben pensarse bajo el signo del género sexual: el hambre y el miedo a engordar. ${ }^{8}$

Frente al cuerpo amenorreico de Inés, el de Lorena desborda: "La gorda siempre se mancha porque no se han creado toallas higiénicas de su talla" (54). El tono burlón de la frase instala la normalización violenta o, mejor dicho, el castigo (no tan) simbólico al que son sometidos constantemente -a través de la moda, el mercado y también el Estado- ciertos cuerpos (los gordos, los femeninos) pero también los pobres y latinoamericanos: "Esas Súper Toallas no llegan a Therox, quizás existan en Nueva York o Miami, donde la moda es muchísimo más democrática, pero acá no." (54). Sin embargo, ese exceso del cuerpo de Vacaflor es percibido por Genoveva como una muestra de trascendencia; es celebrado incluso: “(...) cuando Lorena Vacaflor menstrúa, el aroma [a menstruación] se me hace superior" (54).

\section{Usted no se preocupe, mamita, este es nuestro Tiempo}

En ese tiempo que la novela construye, que es propio y compartido, las alianzas que se tejen engendran formas de afectividad que no están basadas en la conservación obsesiva del cuerpo ajeno -en la prolongación del tiempo- o en el desprecio por las corporalidades no normadas, sino que descansan en la liberación, el respeto por la voluntad o el deseo de la otra, el cuidado y la autodeterminación. No hay moralización de la enfermedad ni moral de la buena forma: "Ya casi desapareciste Inés, ahora podrías ponerte otras metas", le dice Geno. "¿Vos también? Yo también ¿qué? ¿Vas a acosarme? No, tonta, no seas persecuta. Yo nunca. Es más, hay algo que no te he contado, algo sobre el asunto de los ovnis (...). Una decisión radical (...). Yo también estoy pensando en borrarme" (155). La desaparición, el borramiento y la huída se convierten en inflexiones posibles de la fuga de esas normas agotadoras que, como

\footnotetext{
${ }^{8}$ En su novela Las camaleonas (2001), Giovanna Rivero ya había abordado las implicancias de los discursos sobre la belleza y las prácticas farmacotécnicas latinoamericanas, atravesadas por la marginalidad, en los cuerpos femeninos.
} 
sostiene Halberstam (2011, 3), disciplinan el comportamiento y gestionan el desarrollo humano con el objetivo de transformar la infancias "rebeldes" en adultez predecible.

En este mismo sentido, la autodeterminación, en el caso de Genoveva, consiste también en ignorar deliberadamente los pilares básicos del capitalismo contemporáneo (el éxito, las promesas de felicidad y la riqueza) y expresa un deseo de vivir la vida de otra manera. Sin embargo, nuevamente, no ignora por completo su herencia familiar de fracaso, sino que decide desandarla y resignificarla, entendiendo el fracaso no como un hito de clausura que debe ser evitado sino como un espacio habitable y productivo que ofrece alternativas (y otros modos y modalizaciones de lo afectivo) para hacer de la precariedad y la incertidumbre una nueva forma de vida vivible. Así, cargando a su hermano en la espalda como una chola, en pleno abandono de lo conocido, Genoveva se convierte en la sombra "(...) de una jorobada, la de un monstruo feliz y desesperado"(172). A partir de ese momento el futuro se presenta -se hace presentelleno de tiempo: sin linajes, tradiciones ni palabras que den lugar a narrativas de falsa continuidad. La felicidad del monstruo quién sabe a qué mundos obedece.

\section{Bibliografía citada}

AA.VV. 2015. De la tricolor a la wiphala. Buenos Aires: Santiago Arcos.

Athanasiou, Athena. 2015. “¿'Quién’ es aquel nombre? Sujetos de género y resistencia queer, o el deseo de disputa". En Pretérito indefinido: afectos y emociones en las aproximaciones del pasado, Cecilia Macón y Mariela Solana (eds.), 375396. Buenos Aires: Título.

Berlant, Laurent. 2011. El corazón de la nación. Ensayos sobre política y sentimentalismo. México: Fondo de Cultura Económica.

Butler, Judith. 2017. Cuerpos aliados y lucha política. Hacia una teoría performativa de la revuelta. Buenos Aires: Paidós.

Butler, Judith y Athena Athanasiou. 2017. Desposesión: lo performativo en la politica. Buenos Aires: Eterna Cadencia.

Colanzi, Liliana. 2016. Nuestro mundo muerto. Buenos Aires: Eterna Cadencia.

De Mauro Rucovsky, Martín. 2019. Bios precario. Biopolítica y precariedad en Latinoamérica, Tesis doctoral. Facultad de Filosofía y Humanidades: Universidad Nacional de Córdoba. https://ri.conicet.gov.ar/handle/11336/83257.

Edelman, Lee. 2014. No al futuro. Madrid: Egales.

Giorgi, Gabriel. 2014. Formas comunes. Buenos Aires: Eterna Cadencia.

Halberstam, J. 2011.The queer art of failure. Durham: Duke University Press. 
Haraway, Donna. 2019. Las promesas de los monstruos. Ensayos sobre ciencia, naturaleza y otros inadaptables. Barcelona: Holobionte.

Hasbún, Rodrigo. 2009. El lugar del cuerpo. Buenos Aires: Alfaguara.

Kristeva, Julia. 1998. El porvenir de la revuelta. Buenos Aires: Fondo de Cultura Económica.

Morini, Cristina. 2015. Por amor o a la fuerza. Feminización del trabajo y biopolitica del cuerpo. Madrid: Traficantes de sueños.

Puenzo, Lucía. 2014 [2004]. El niño pez. Buenos Aires: Beatriz Viterbo.

Quintana, Isabel. 2020. "Lo residual como gesto crítico: un porvenir de los restos". En Historia feminista de la literatura argentina. En la intemperie: poéticas de la fragilidad y la revuelta, Laura Arnés, Lucía De Leone y María José Punte (eds.), 137-149. Villa María: Eduvim.

Rivero Santa Cruz, Giovanna. 2014. 98 segundos sin sombra. Barcelona: Penguin Random House.

- 2020. Tierra fresca de su tumba. Buenos Aires: Marciana.

Roudinesco, Élisabeth. 2010. La familia en desorden. Buenos Aires: Fondo de Cultura Económica.

Sosa Villada, Camila. 2019. Las malas. Buenos Aires: Tusquets.

Suez, Perla. 2015. El país del diablo. Buenos Aires: Edhasa.

Urrelo Zárate, Wilmer. 2011. Hablar con los perros. Buenos Aires: Alfaguara.

Venturini, Aurora. 1992. Nosotros, los Caserta. Buenos Aires: Mondadori.

-2007. Las primas. Buenos Aires: Mondadori. 